\title{
Investigations of Glasses in the System $\mathrm{PbO}-\mathrm{PbF}_{2}$
}

\author{
By B. Govinda Rao, H. G. Keshava Sundar and Kalya J. Rao* \\ Solid State and Structural Chemistry Unit, Indian Institute of Science, \\ Bangalore 560012, India
}

Received 11th May, 1984

\begin{abstract}
Glass formation in the system $\mathrm{PbO}-\mathrm{PbF}_{2}$ has been investigated. The structure of these glasses has been studied using X-ray diffraction. Densities, heat capacities, glass-transition and crystallization temperatures and Vicker's microhardnesses have been measured. D.c. conductivities of these glasses have also been measured as a function of temperature. A structural model has been developed which suggests the existence of $\left[\mathrm{PbO}_{2} \mathrm{~F}_{4}\right]$-type units over the entire composition range. It is suggested that covalent linkages of the type $-\mathrm{O}-\mathrm{Pb}-\mathrm{O}-$ play a crucial role in determining the composition limits to glass formation. The structural model has been shown to be consistent with other physical properties of the glasses.
\end{abstract}

Lead oxide is not a glass-forming oxide by itself, but it can be incorporated ${ }^{1}$ in substantial quantities into other glass-forming oxide systems such as silicates, borates and phosphates. Lead fluoride has also been used as a constituent of some glass-forming binary and ternary fluoride systems. ${ }^{2,3}$ However, there has been no report to our knowledge of any study of glasses made from the binary system $\mathrm{PbO}-\mathrm{PbF}_{2}$. We have previously reported ${ }^{4}$ glass formation in the similar system $\mathrm{PbO}-\mathrm{PbCl}_{2}$. Recently fluoride ions have been reported to participate in network formation in silicate glasses, ${ }^{5}$ while it is known that fluoride ions act as bridges in $\mathrm{BeF}_{2}$ glasses. ${ }^{6}$ Hence we suspect that glass formation in the $\mathrm{PbO}-\mathrm{PbF}_{2}$ system may be even more extensive than in the $\mathrm{PbO}-\mathrm{PbCl}_{2}$ system. The phase diagram ${ }^{7}$ for the $\mathrm{PbO}-\mathrm{PbF}_{2}$ system is very simple, with a single eutectic at $54 \mathrm{~mol} \%$ lead oxide; the eutectic temperature is $767 \mathrm{~K}$. There is no indication of compound formation in the entire binary phase field. ${ }^{8}$ Glass formation may therefore be expected to be easier in this system because of the absence of any tendency towards crystallization. From the chemical point of view also glass formation in the $\mathrm{PbO}-\mathrm{PbF}_{2}$ system should be interesting because $\mathrm{PbO}$ is known to be highly covalent whereas $\mathrm{PbF}_{2}$ is typically ionic. In pure (both yellow and red) $\mathrm{PbO}$ lead atoms are bonded to four oxygen atoms, giving rise to a puckered layer structure ${ }^{9}$ with large van der $\mathrm{Waals}(\mathrm{Pb}-\mathrm{Pb})$ interactions. In yellow $\mathrm{PbO}$ it has been suggested that an overlap of empty and filled $s p^{3} d^{2}$ hybridized orbitals from neighbouring lead atoms also occurs. $\mathrm{PbF}_{2}$, on the other hand, has a structure ${ }^{9}$ in which lead ions are coordinated to nine fluoride ions at typically ionic distances. Thus the glasses formed in this system may be expected to be characterized by a continuous decrease in covalent linkages as the $\mathrm{PbF}_{2}$ content increases unless two chemically distinct types of lead atoms are present. For glass compositions rich in lead fluoride, which may be suspected to be quite ionic, the similarity in the sizes of the $\mathrm{O}^{2-}$ and $\mathrm{F}^{-}$ions may be expected to become a contributing factor in increasing the configurational entropy and hence the glass-forming tendency. It is also possible that the structural roles of the fluoride and oxygen ions in such glass compositions become very similar. A study of glass formation in this system should therefore be very interesting. 
In this paper we report and discuss various characterization studies of $\mathrm{PbO}-\mathrm{PbF}_{2}$ glasses, i.e. glass formation, molar volume, microhardness, glass-transition and crystallization temperatures, temperature variation of the d.c. conductivity and heat capacity for various compositions. We have also performed a structural characterization of these glasses by X-ray diffraction using $\mathrm{Cu} K_{\alpha}$ radiation. We have developed a structural model which is very similar to that of $\mathrm{PbO}-\mathrm{PbCl}_{2}$ glasses and which is consistent with the physical properties of glasses discussed in this study.

\section{EXPERIMENTAL}

\section{PREPARATION}

The starting materials used in the preparation of the glasses were $\mathrm{Pb}_{3} \mathrm{O}_{4}$ (A.R.) and $\mathrm{PbF}_{2}$ (A.R.). It was first confirmed that the $\mathrm{Pb}_{3} \mathrm{O}_{4}$ decomposes to yellow $\mathrm{PbO}$ completely at $c a .840 \mathrm{~K}$. Appropriately weighed quantities of $\mathrm{Pb}_{3} \mathrm{O}_{4}$ and $\mathrm{PbF}_{2}$ were mixed thoroughly and melted in short quartz tubes using an oxyacetylene flame till a uniformly clear melt was obtained. The melt was kept at this temperature $(\mathrm{ca} .900-1000 \mathrm{~K})$ for a short time $(2-3 \mathrm{~min})$, poured on to a polished steel plate and pressed quickly with a polished steel block. Small drops of the melt were also found to quench easily into shiny, slightly yellow transparent beads which were used for density measurements. There was no noticeable reaction of the melt with the walls of the quartz tube. However, the infrared spectra of these glasses show a peak at $c a .860 \mathrm{~cm}^{-1}$ which may be attributed to $\mathrm{Si}-\mathrm{O}$ stretching as in $\mathrm{PbO} \cdot x \mathrm{SiO}_{2}$ glasses ${ }^{10}$ where $x$ is very low. We have measured the weight loss of the quartz tube used for the preparation. It is estimated that, in deliberately prolonged heating of the melt at $c a .1000 \mathrm{~K}$, a maximum of $c a .4 \mathrm{~mol} \% \mathrm{SiO}_{2}$ is incorporated into the resulting glass. Our attempts to obtain these glasses by melting the batch in a platinum crucible were not successful as the melt was almost always partially reduced to metallic lead upon heating. We have listed the nominal compositions of these glasses in terms of $\mathrm{PbO}$ and $\mathrm{PbF}_{2}$ and have ignored the $\mathrm{SiO}_{2}$ content, which is treated here as an unavoidable impurity.

\section{DENSITIES AND MICROHARDNESSES}

Densities were determined by pyknometry with xylene as filling liquid. Glass beads free of any detectable bubbles were used for density determination. Microhardnesses were determined by Vicker's method, employing a Carl Zeiss (Jena) m.h.p. 160 microhardness tester. A uniform load of $100 \mathrm{~g}$ was applied to make indentations on $c a .1 \mathrm{~mm}$ thick flat discs of glass. The results reported here are averages of measurements made with 4 or 5 distinct symmetrical indentations for each glass composition.

\section{X-RAY DIFFRACTION}

A standard Philips diffractometer equipped with a goniometer of the type PW1373 was used for recording $\mathrm{X}$-ray intensities. The scanning rate was $0.5^{\circ} \mathrm{min}^{-1}$ and the intensities were recorded in the range $10 \leqslant 2 \theta /{ }^{\circ} \leqslant 120$ with $\mathrm{Cu} K_{\alpha}$ radiation using an Ni filter. Details of the procedure adopted for data treatment have been reported in our earlier paper. ${ }^{11}$ The pair distribution functions were calculated using the following formula:

where

$$
2 \pi^{2} r \rho^{\mathrm{e}}(r) \underset{\text { u.c. }}{\Sigma} Z_{j}=2 \pi^{2} r \rho_{0}^{\mathrm{e}} \sum Z_{\text {u.c. }} Z_{j}+\int_{0}^{k_{\mathrm{m}}} k i(k) \sin (r k) \mathrm{d} k
$$

and

$$
i(k)=A\left[I(k)-S(k)-\left\{\sum_{\text {u.c. }} f^{2}(k)+\sum_{\text {u.c. }} I_{\text {inc }}(k)\right\}\right] / g^{2}(k)
$$

$$
g(k)=\sum_{\text {u.c. }} f(k) / \sum_{\text {u.c. }} f(0)
$$

In eqn (1)-(3) $k=4 \pi \sin \theta / \lambda, k_{\mathrm{m}}$ is its maximum value (in the present case $k_{\mathrm{m}} \approx 7.0 \AA^{-1}$ ), $f(k)$ is the scattering factor, $I_{\text {inc }}$ is the incoherent intensity, $Z$ is the atomic number, $I(k)$ is the 
Table 1. Density, molar volume, Vicker's microhardness, d.c. conductivity, activation energy and $\sigma_{0}$ value for different glass compositions

\begin{tabular}{cccccc}
\hline $\begin{array}{c}\text { composition } \\
\mathrm{PbO}: \mathrm{PbF}_{2}\end{array}$ & $\begin{array}{c}\text { density } \\
/ \mathrm{g} \mathrm{cm}^{-3}\end{array}$ & $\begin{array}{c}\text { Vickers } \\
\text { molar volume } \\
/ \mathrm{cm}^{3}\end{array}$ & $\begin{array}{c}\text { activation } \\
\text { microhardness } \\
/ \mathrm{kg} \mathrm{mm}^{-2}\end{array}$ & $\begin{array}{c}\text { energy } \\
/ \mathrm{eV}\end{array}$ & $\sigma_{0} / 10^{4} \Omega^{-1} \mathrm{~cm}^{-1}$ \\
\hline $30: 70$ & 7.21 & 33.09 & $186 \pm 10$ & 0.67 & 3.84 \\
$40: 60$ & 7.32 & 32.29 & $204 \pm 10$ & - & - \\
$50: 50$ & 7.40 & 31.74 & $210 \pm 10$ & 0.68 & 1.95 \\
$60: 40$ & 7.54 & 30.77 & $244 \pm 10$ & - & - \\
$70: 30$ & 7.73 & 29.73 & $230 \pm 10$ & 0.74 & 1.57 \\
$80: 20$ & 7.88 & 28.88 & $235 \pm 10$ & 0.91 & 4.77 \\
\hline
\end{tabular}

X-ray intensity function corrected for background, absorption and polarization and u.c. indicates that the summation is over unit composition. The average electron density, $\rho_{0}^{\mathrm{e}}$, is calculated from the density of the glass. $A$ in eqn (2) is a normalizing constant. The constants in parametrized $S(k)$ were determined by methods described earlier. ${ }^{11}$ The ripples in the low- $r$ region (up to $1.5 \AA$ ) were minimized.

\section{HEAT CAPACITIES}

Heat capacities were determined using a Perkin-Elmer DSC-II scanning calorimeter employing sapphire as standard. For these measurements $c a .100 \mathrm{mg}$ of the samples annealed at a temperature $20 \mathrm{~K}$ below $T_{\mathrm{g}}$ were used. A uniform heating rate of $10 \mathrm{~K} \mathrm{~min}^{-1}$ was employed. Measurements were made over the temperature range $400-580 \mathrm{~K}$. The intersection point of the extended linear regions around the glass-transition elbow was taken as the glass-transition temperature, $T_{\mathrm{g}}$. The change in the heat capacities, $\Delta C_{p}$, at $T_{\mathrm{g}}$ was measured for all the samples. The first crystallization temperature for each glass has also been noted.

\section{D.C. CONDUCTIVITY}

For conductivity measurements the glasses were prepared as thin discs of $0.5 \mathrm{~mm}$ thickness. The conductivity cell and measuring technique have been discussed elsewhere. ${ }^{12}$ The resistances were calculated by measuring the current through the sample for a known applied voltage $(5 \mathrm{~V})$ using a Keithley 616 digital electrometer. The current was passed for only very brief periods $(<30 \mathrm{~s})$ in order to avoid polarization. Conductivities were measured beyond the glass transition and up to temperatures at which the samples were either deformed under the load of the springs on the electrodes or crystallized, rendering further measurements inaccurate.

\section{RESULTS AND DISCUSSION}

Density, molar volume, Vicker's microhardness, activation energy of conductivity and values of $\sigma_{0}$ are listed in table 1 . The thermodynamic quantities, such as the glass-transition temperature $\left(T_{\mathrm{g}}\right)$, crystallization temperature $\left(T_{\mathrm{cr}}\right)$, heat capacity $\left(C_{p}\right)$ at $20 \mathrm{~K}$ below $T_{\mathrm{g}}$ and change in heat capacity $\left(\Delta C_{p}\right)$ at $T_{\mathrm{g}}$ for various compositions are listed in table 2 . The quantity $\left(T_{\mathrm{cr}}-T_{\mathrm{g}}\right)$ is also been listed in table 2 .

\section{GLASS FORMATION}

The range of glass formation extends from 80 to $30 \mathrm{~mol} \% \mathrm{PbO}$. This range is considerably larger than in the $\mathrm{PbO}-\mathrm{PbCl}_{2}$ system, particularly on the lead-halide-rich side. Therefore it appears that the fluoride system is a better glass-former than the chloride system. This experimental observation is consistent with the structural features of these glasses discussed below. Fluorine may tend to occupy the bridging position at high $\mathrm{PbF}_{2}$ compositions, helping glass formation. 
Table 2. Thermodynamic quantities for various glass compositions

\begin{tabular}{cccccc}
\hline $\begin{array}{c}\text { composition } \\
\mathrm{PbO}: \mathrm{PbF}_{2}\end{array}$ & $T_{\mathrm{g}} / \mathrm{K}$ & $T_{\mathrm{cr}} / \mathrm{K}$ & $\left(T_{\mathrm{cr}}-T_{\mathrm{g}}\right) / \mathrm{K}$ & $\begin{array}{c}C_{p} \text { below } T_{\mathrm{g}} \\
/ \mathbf{J}^{\mathbf{m o l}} \mathbf{K}^{-1}\end{array}$ & $\begin{array}{c}\Delta C_{p} \\
/ \mathrm{J} \mathrm{mol}^{-1} \mathrm{~K}^{-1}\end{array}$ \\
\hline $30: 70$ & 460 & 545 & 85 & 78.7 & 38 \\
$40: 60$ & 487 & 609 & 122 & 77.9 & 36 \\
$50: 50$ & 491 & 584 & 113 & 75.0 & 34 \\
$60: 40$ & 514 & 588 & 74 & 72.0 & 33 \\
$70: 30$ & 537 & 574 & 37 & 73.0 & 30 \\
$80: 20$ & 545 & 574 & 29 & 72.6 & 28 \\
\hline
\end{tabular}

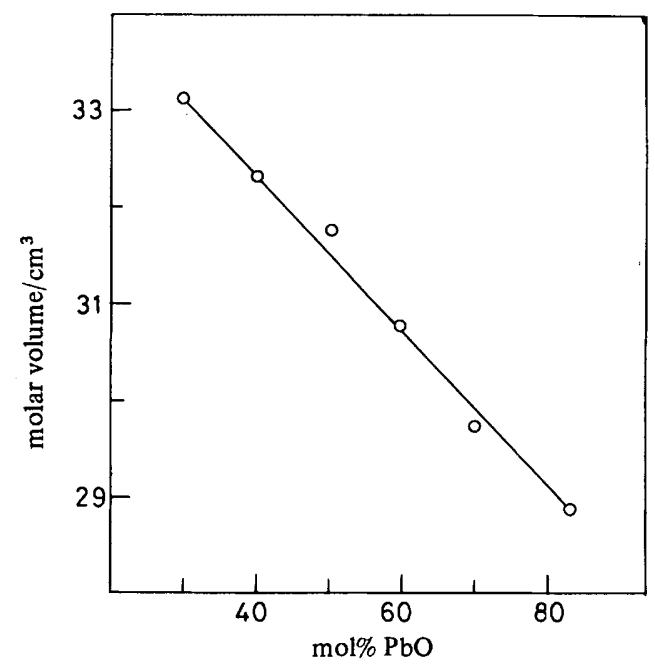

Fig. 1. Variation of molar volume with glass composition.

\section{DENSITIES AND MOLAR VOLUMES}

The molar volumes of the glasses were evaluated from their densities and are plotted against glass composition in fig. 1. The extrapolated molar volumes give the densities of the hypothetical glasses $\mathrm{PbO}$ and $\mathrm{PbF}_{2}$ as 8.12 and $6.92 \mathrm{~g} \mathrm{~cm}^{-3}$, respectively, values which are lower than the densities of the corresponding crystalline components ( $9.53 \mathrm{~g} \mathrm{~cm}^{-3}$ for tetragonal $\mathrm{PbO}$ and $8.24 \mathrm{~g} \mathrm{~cm}^{-3}$ for $\mathrm{PbF}_{2}$ ). It is surprising that the ratios of the densities of the extrapolated glasses to those of the corresponding crystalline phases are 0.85 for $\mathrm{PbO}$ and 0.84 for $\mathrm{PbF}_{2}$. These values correspond to the ratio of the space-filling efficiency of random close packing $(0.63)$ to the spacefilling capacity of the ordered face-centred cubic or hexagonal close packing $(0.74)$ arrangement of simple spheres. In this context note that the radii of the $\mathrm{Pb}^{2+}(1.20 \AA)$, $\mathrm{O}^{2-}(1.32 \AA)$ and $\mathrm{F}^{-}(1.33 \AA)$ ions are rather similar. A simple random close packing arrangement of such ions increases the volume by $c a .15 \%$ compared with a close-packed crystalline arrangement. Such an increase in volume lowers the cohesive energy by $c a .5 \%$. This energy is $c a .146 \mathrm{~kJ}$ for a typical $50 \mathrm{PbO} \cdot 50 \mathrm{PbF}_{2}$ glass (lattice energies of $\mathrm{PbO}$ and $\mathrm{PbF}_{2}$ are 3251 and $2469 \mathrm{~kJ} \mathrm{~mol}^{-1}$, respectively). Such a large energy difference between crystalline and glassy states of the same material may be 


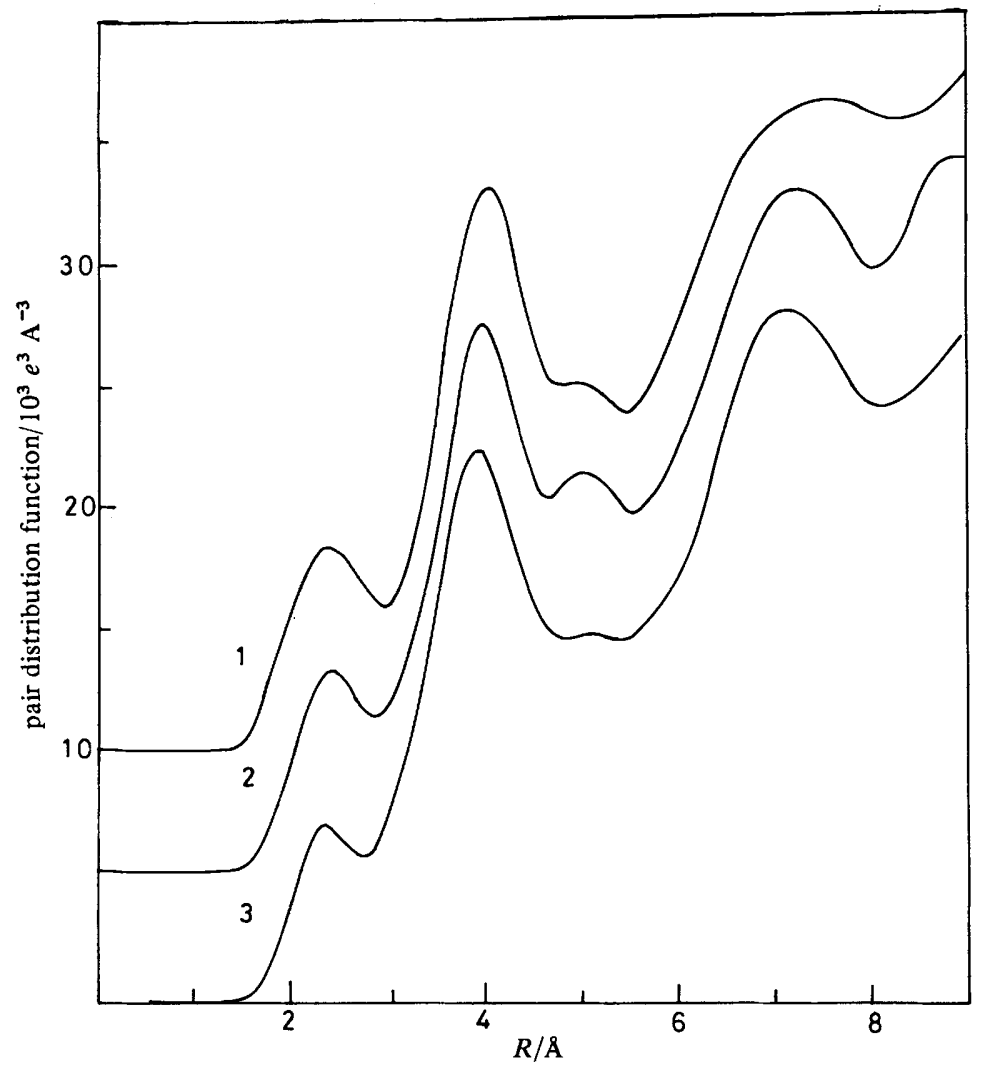

Fig. 2. Pair distribution functions for various glass compositions: (1) $30 \mathrm{PbO} \cdot 70 \mathrm{PbF}_{2}$, (2) $50 \mathrm{PbO} \cdot 50 \mathrm{PbF}_{2}$ and (3) $80 \mathrm{PbO} \cdot 20 \mathrm{PbF}_{2}$. The plots are displaced systematically by 5 units on the $y$-axis from (2) to (1).

considered as unphysical. Therefore we feel that the observed correspondence to the random-close-packing volume may arise from the presence of small atomic groupings of higher cohesive energy, which in turn are probably present in a random-closepacked assemblage. X-ray diffraction results discussed below support this possibility.

\section{X-RAY DIFFRACTION AND STRUCTURAL MODEL FOR THE GLASSES}

The pair distribution functions (p.d.f.) determined in the manner described earlier are given in fig. 2 for three compositions, $30 \mathrm{PbO}, 50 \mathrm{PbO}$ and $80 \mathrm{PbO}$, which span the entire range of glass composition investigated here. The p.d.f. for other compositions are very similar. Upon a cursory examination we note that the most striking feature of these p.d.f. is their similarity to those of $\mathrm{PbO}-\mathrm{PbCl}_{2}$ glasses, the structure of which has been reported by us elsewhere. ${ }^{13}$ The positions of the first four peaks around 2.3 , 4.0, 5.0 and $7.0 \AA$ remain largely unaltered. The intensity of the first peak increases with increasing $\mathrm{PbF}_{2}$ content. The intensity of the second peak is high and remains almost constant for all compositions. The third peak is of rather low intensity and the fourth peak is intense and broad. The positions of the third and fourth peaks also remain unaffected by variations in composition.

From a knowledge of the crystal structures ${ }^{9}$ of $\mathrm{PbO}$ and $\mathrm{PbF}_{2}$, the first peak at 
ca. $2.30 \AA$ can be attributed to the $\mathrm{Pb}-\mathrm{O}$ and $\mathrm{Pb}-\mathrm{F}$ distances, as the $\mathrm{Pb}-\mathrm{O}$ distance in $\mathrm{PbO}$ is $c a .2 .30 \AA$ and the $\mathrm{Pb}-\mathrm{F}$ distance in $\mathrm{PbF}_{2}$ varies between 2.41 and $2.69 \AA$ (mean $2.55 \AA$ ). Pair distances of the type $\mathrm{O}-\mathrm{F}$ may also contribute to the intensity of the first peak. The second peak at ca. $4.0 \AA$, being the most intense, can be attributed to $\mathrm{Pb}-\mathrm{Pb}$. While the integrated intensity of the first peak increases by a factor of two on increasing the $\mathrm{PbF}_{2}$ content from 20 to $70 \mathrm{~mol} \%$, the intensity of the second peak remains almost constant. The substitution of $\mathrm{PbO}$ by $\mathrm{PbF}_{2}$ introduces twice the number of (fluoride) anions, thereby increasing the number of scattering pairs contributing to the first peak (the scattering factors of $\mathrm{O}^{2-}$ and $\mathrm{F}^{-}$ions being very similar). Hence the intensity of the first peak increases with $\mathrm{PbF}_{2}$. The intensity of the second peak remains almost constant because the concentration of lead ions remains constant for all compositions. The third and fifth peaks may contain contributions from various pair distances such as $\mathrm{Pb}-\mathrm{Pb}$ in different $\left[\mathrm{FPb}_{x}\right]$ units where $x$ may vary from 3 to 6 (as discussed later). Guided by the close similarity of the general features of the p.d.f. of these glasses to those of $\mathrm{PbO}-\mathrm{PbCl}_{2}$ glasses, ${ }^{13}$ we propose the following structural model. (1) Covalent $-\mathrm{O}-\mathrm{Pb}-\mathrm{O}-$ linkages are crucial for glass formation and are present in all glasses. (2) Oxygen atoms are present in $\left[\mathrm{OPb}_{4}\right]$-type tetrahedra because the former is primarily responsible for establishing network features through covalent bonding using their $s p^{3}$ hybridized orbitals. (3) Lead atoms possess an anion coordination of six (a value between those in crystalline $\mathrm{PbO}$ and in $\mathrm{PbF}_{2}$ ) in all glasses. EXAFS and XANES studies ${ }^{14,15}$ of $\mathrm{PbO}-\mathrm{PbCl}_{2}$ glasses have shown that six-coordinated lead is quite consistent. As the lead ion is usually connected to two oxygens, the other four ions surrounding it must be fluoride ions. Hence $\left[\mathrm{PbO}_{2} \mathrm{~F}_{4}\right]$-type octahedra are assumed to be present in the entire range of glass composition. (4) The coordination number of the fluoride ion varies with composition, being high in $\mathrm{PbO}$-rich glasses and low in $\mathrm{PbF}_{2}$-rich glasses.

$\mathrm{PbO}$ itself does not have enough lead atoms to provide a three-dimensional network of the type $\mathrm{OPb}_{2}$ (analogous to $\mathrm{SiO}_{2}$ ) built with corner-shared oxygen tetrahedra as the base. However, with the addition of $\mathrm{PbF}_{2}$ it is possible to consider that the structure is built up towards $\left[\mathrm{OPb}_{2}\right] \mathrm{F}_{2}$, in which a tetrahedral network can exist. The fluoride ions are suitably distributed around the lead ions while the network is formed by $\left[\mathrm{OPb}_{2}\right]^{2+}$. Indeed, for this particular composition of glass, corresponding to $50 \mathrm{PbO} \cdot 50 \mathrm{PbF}_{2}$, the coordination number of the fluoride ion will also be four if we consider that the lead ion is present in an octahedral coordination of the type $\left[\mathrm{PbO}_{2} \mathrm{~F}_{4}\right]$. This ensues from the following relation, which is based on one of Pauling's bonding rules. ${ }^{16}$ For a glass of composition $(1-x) \mathrm{PbO} \cdot x \mathrm{PbF}_{2}$ :

$$
n_{\mathrm{Pb}}=(1-x) n_{\mathrm{O}}+2 n_{\mathrm{F}}
$$

where $n$ is the number of bonds reaching (or emanating from) the subscripted atom. With $<50 \mathrm{~mol} \% \mathrm{PbF}_{2}$ we consider that distorted $\left[\mathrm{OPb}_{4}\right]$ tetrahedra share edges. Since the ratio of the number of lead ions to fluoride ions is quite high, fluoride ions occupy positions that enable them to acquire high coordination numbers (with $\mathrm{Pb}$ atoms). Indeed, it can be calculated from eqn (4) for the specific case of $75 \mathrm{PbO} \cdot 25 \mathrm{PbF}_{2}$ that the coordination number for the fluoride ion is six. For compositions with $>50 \mathrm{~mol} \%$ $\mathrm{PbF}_{2},\left[\mathrm{OPb}_{4}\right]$ tetrahedra must have unshared corners and the dimensionality of the network is gradually reduced. On addition of $60 \mathrm{~mol} \%$ of $\mathrm{PbF}_{2}$ we would expect that $\left[\mathrm{OPb}_{4}\right]$ tetrahedra would have only three shared corners, so that the glasses possess a two-dimensional structure analogous to that of chalcogenide glasses. By the same argument, addition of $66.6 \mathrm{~mol} \% \mathrm{PbF}_{2}$ would lead to a structure where only the integrity of the $-\mathrm{O}-\mathrm{Pb}-\mathrm{O}-$ chains is retained. Further addition of $\mathrm{PbF}_{2}$ would degrade the chains to shorter lengths, and for a composition with $c a .71 .5 \mathrm{~mol}_{\mathrm{o}}^{\mathrm{P}} \mathrm{PbF}_{2}$ 
the structure would possess only corner-shared dimers of $\left[\mathrm{OPb}_{4}\right]$ tetrahedra. Hence this composition corresponds to an extreme limit where the degradation of network features is almost complete. Note from fig. 6 (see later) that $\left(T_{\mathrm{cr}}-T_{\mathrm{g}}\right)$, which is considered ${ }^{17}$ as a measure of glass stability and indirectly glass formation, is highest at $c a .50-60 \mathrm{~mol} \% \mathrm{PbF}_{2} .\left(T_{\mathrm{cr}}-T_{\mathrm{g}}\right)$ decreases sharply on either side of this region. The highest percentage of $\mathrm{PbF}_{2}$ for which a reasonably good glass could be obtained is ca. $70 \%$, in remarkable agreement with the composition limit to the presence of network features in the model. However, we suspect that fluorine begins to play the role of oxygen in $\mathrm{PbF}_{2}$-rich compositions where the fluoride-ion coordination decreases rapidly to $c a$. 3.5 .

Such a model is consistent with the observed pair distribution functions of the glasses. Since the $\mathrm{Pb}-\mathrm{F}$ and $\mathrm{Pb}-\mathrm{O}$ distances in the model should remain unaltered except for $\mathrm{PbF}_{2}$-rich glasses (where fluoride ions may play the part of oxygens) a slightly greater distribution of distances and hence a slightly broader peak results. However, both the nature of the $\left[\mathrm{PbO}_{2} \mathrm{~F}_{4}\right]$ octahedra and the possible effects of composition on the covalency of the $-\mathrm{O}-\mathrm{Pb}-\mathrm{O}-$ linkages should be established by the further experiments.

\section{D.C. CONDUCTIVITY}

The variation in d.c. conductivity with temperature for different glass compositions is shown in fig. 3. Curve-fitted values of the activation energy $(\Delta E)$ and $\sigma_{0}$ for the linear portion of the graph for various compositions are listed in table 1 . Note that $\log \sigma T$ varies quite linearly with $1 / T$ up to a temperature a few degrees (40-50 K) below $T_{\mathrm{g}}$. ( $T_{\mathrm{g}}$ values for different compositions are marked by arrows in the figure). Note also that the conductivities are quite high and are comparable to those of fast ion conducting glasses. ${ }^{18}$ The isothermal conductivity also increases systematically with increasing $\mathrm{PbF}_{2}$ content in the glass. Since $\mathrm{F}^{-}$ions may be considered as dominant charge carriers in these glasses, such a variation in conductivity is quite expected. Activation energies also decrease monotonically with $\mathrm{PbF}_{2}$ content in the glass and this variation is consistent with our structural model discussed in the earlier section. With the addition of $>50 \mathrm{~mol}_{\%} \% \mathrm{PbF}_{2}$, the glass structure becomes more open as additional $\mathrm{PbF}_{2}$ breaks the $-\mathrm{O}-\mathrm{Pb}-\mathrm{O}$ - linkages. The coordination number of $\mathrm{F}^{-}$ ions also decreases. Hence the activation energy decreases with the addition of $\mathrm{PbF}_{2}$. Values of $\sigma_{0}$ are comparatively high and are of the same order for all the compositions, suggesting that the environment which mobile $\mathrm{F}^{-}$ions explore during transport is common to all glass-forming compositions. This is in agreement with the existence of $\left[\mathrm{PbO}_{2} \mathrm{~F}_{4}\right]$-type octahedra at all glass-forming compositions.

\section{HEAT CAPACITIES AND GLASS TRANSITIONS}

Heat capacities obtained from d.s.c. measurements are plotted in fig. 4 as a function of temperature for various compositions. Up to $T_{\mathrm{g}}$ the increase in $C_{p}$ is very marginal, suggesting that the Debye temperatures of these glasses are well below $T_{\mathrm{g}}$. Heat-capacity values $20 \mathrm{~K}$ below their respective $T_{\mathrm{g}}$ are plotted in fig. 5 for the various glasses. Variation of the Dulong-Petit heat capacity with composition is also shown in fig. 5 for comparison. The heat-capacity behaviour clearly brings out the following points. (1) $C_{p}$ varies very little with composition. (2) The true $C_{p}$ below $T_{\mathrm{g}}$ being higher than the Dulong-Petit heat capacity reflects the fact that a part of the liquid configurational heat capacity is frozen into glasses at their respective glass-transition temperatures. (3) The magnitude of the excess heat capacity, which we thus attribute to a configurational origin, is systematically higher in PbO-rich glasses. We consider the latter observation to be significant because the $\mathrm{PbO}$-rich glasses may be expected to 


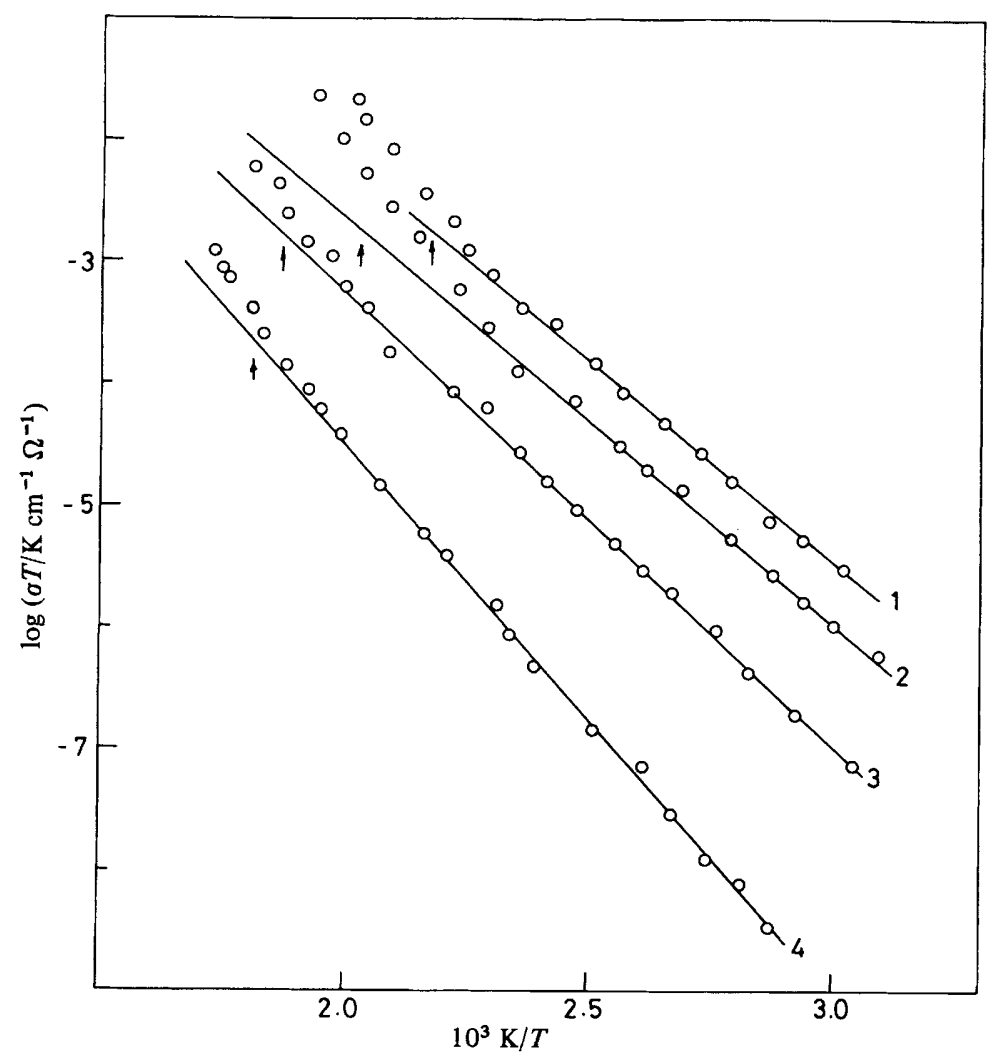

Fig. 3. Temperature variation of d.c. conductivity for various glass compositions: (1) $30 \mathrm{PbO} \cdot 70 \mathrm{PbF}_{2}$, (2) $50 \mathrm{PbO} \cdot 50 \mathrm{PbF}_{2}$, (3) $70 \mathrm{PbO} \cdot 30 \mathrm{PbF}_{2}$ and (4) $80 \mathrm{PbO} \cdot 20 \mathrm{PbF}_{2}$.

be more covalent and hence are characterized by larger magnitudes of frozen configurational heat capacity. This is in keeping with similar observations made by Angell and Sichina ${ }^{19}$ with regard to covalently bonded glasses.

The change in heat capacity at $T_{\mathrm{g}}$ is also plotted against $\mathrm{mol} \% \mathrm{PbO}$ in fig. $5 . \Delta C_{p}$ is higher for $\mathrm{PbF}_{2}$-rich glasses and decreases with $\mathrm{mol} \% \mathrm{PbO}$. This may again be interpreted as due to higher covalency of bonding in $\mathrm{PbO}$-rich glasses because highly covalent glasses are known to exhibit weak step-like increases in $C_{p}$ at their glass transitions.

The variation of $T_{\mathrm{g}}$ with composition is shown in fig. $6 . T_{\mathrm{g}}$ values are generally high, although lower than those of $\mathrm{PbO}-\mathrm{PbCl}_{2}$ glasses, and increase with $\mathrm{PbO}$ content. A systematic rise of $85 \mathrm{~K}$ in $T_{\mathrm{g}}$ is registered between extreme compositions. Note that $T_{\mathrm{g}}$ varies linearly, although the liquidus temperature exhibits a minimum at $767 \mathrm{~K}$ for the eutectic composition $54 \mathrm{~mol} \% \mathrm{PbO}$. The approximate constancy of the ratio between $T_{\mathrm{g}}$ and liquidus temperature observed in many glass-forming systems with a variety of bonding characteristics is not obeyed by the glasses in this system. However, the molar cohesive energy calculated to a first approximation as a sum of lattice energies of the components weighted by their molar percentages varies in the same manner as $T_{\mathrm{g}}$. Variation of the glass-transition temperature may also be considered in the light of the cluster model. ${ }^{20}$ Briefly, in the cluster model glass is considered to be made up of clusters, which form a large part of the glass, and tissue 


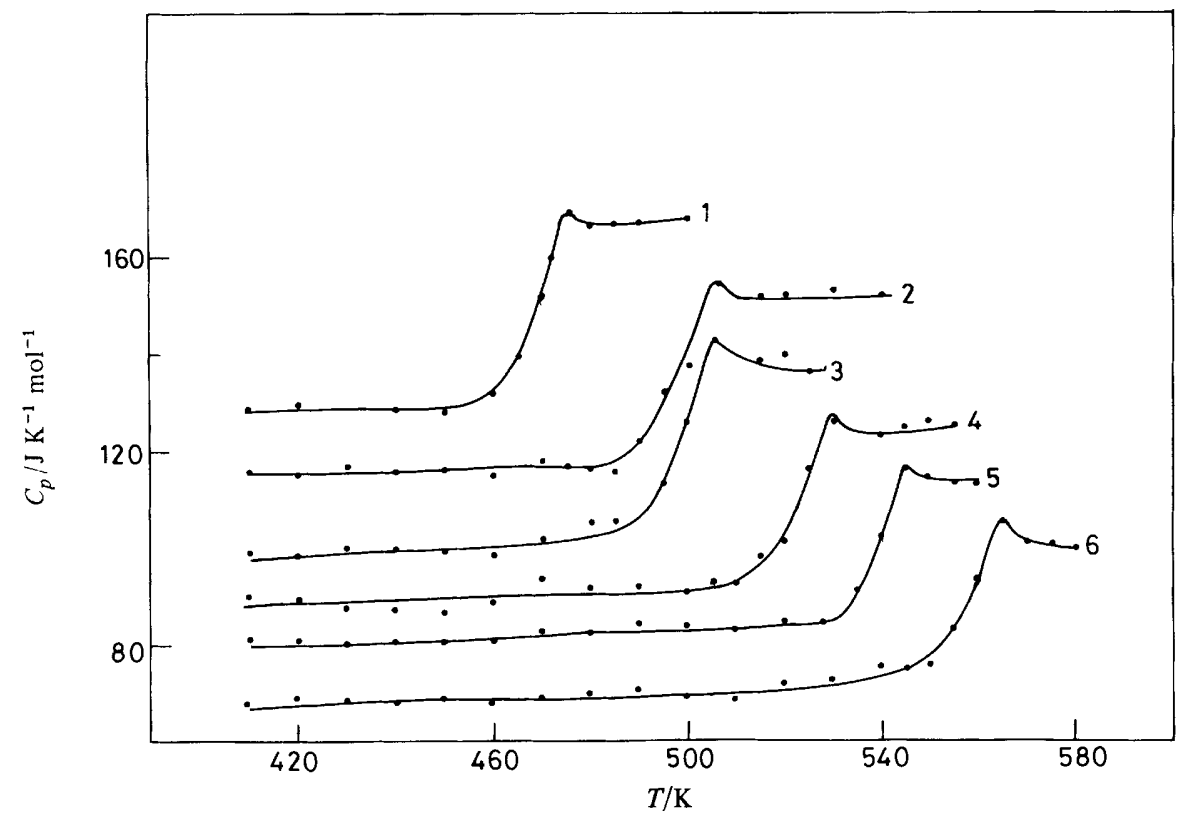

Fig. 4. Temperature variation of heat capacity for various glass compositions: (1) $30 \mathrm{PbO} \cdot 70 \mathrm{PbF}$, (2) $40 \mathrm{PbO} \cdot 60 \mathrm{PbF}_{2}$, (3) $50 \mathrm{PbO} \cdot 50 \mathrm{PbF}_{2}$, (4) $60 \mathrm{PbO} \cdot 40 \mathrm{PbF}_{2}$, (5) $70 \mathrm{PbO} \cdot 30 \mathrm{PbF}_{2}$ and (6) $80 \mathrm{PbO} \cdot 20 \mathrm{PbF}_{2}$. The plots are displaced systematically by 40 units on the $y$-axis from (5) to (1).

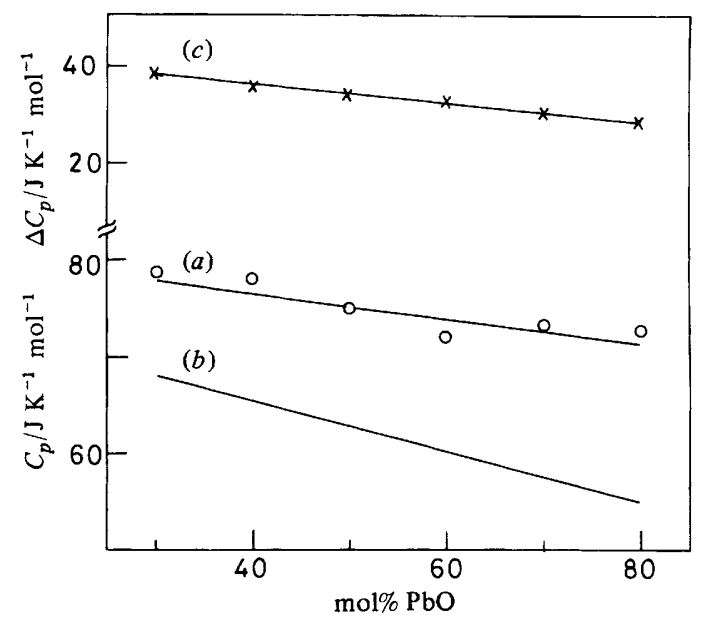

Fig. 5. (a) Variation of heat capacity $20 \mathrm{~K}$ below $T_{\mathrm{g}}$ with glass composition. (b) Variation of calculated Dulong-Petit $(3 n \boldsymbol{R})$ heat capacity with glass composition. $(c)$ Variation of change in heat capacity with composition.

material of the same composition, which binds the clusters. Clusters in highly ionic glasses possess ordered structures and their sizes are ca. 50-100 A. Particles in the tissue region are in a state of complete positional disorder and vibrate in highly anharmonic potential wells, and their vibratory motion ultimately evolves into translation. Particles in the cluster gradually populate the vibrational manifold of the tissue 


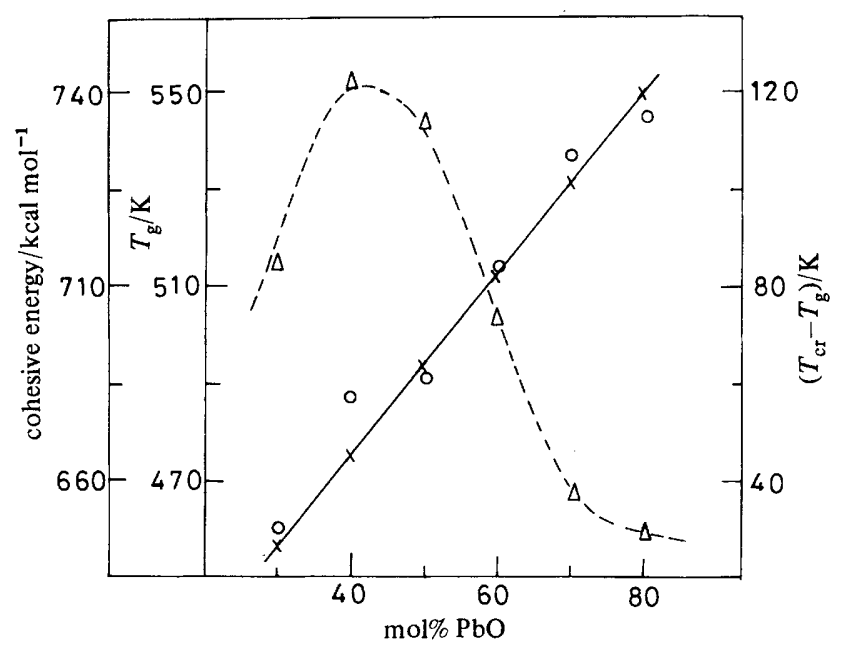

Fig. 6. Variations of glass-transition temperature $(O)$, cohesive energy $(x)$ and the quantity $\left(T_{\mathrm{cr}}-T_{\mathrm{g}}\right)(\triangle)$ with glass composition.

material and the glass transition occurs when the clusters melt. The quantity which determines $T_{\mathrm{g}}$ in this model [see ref. (20) for details] is the vibrational frequency of the most mobile ion, which we may assume in the present case to be $\mathrm{F}^{-}$. We presume that the clusters are made up of a suitable and small conglomerate of $\left[\mathrm{PbO}_{2} \mathrm{~F}_{4}\right]$ units. That $T_{\mathrm{g}}$ decreases as the $\mathrm{PbO}$ content decreases in the glass suggests that the vibrational frequency of the $\mathrm{F}^{-}$ion (in the cationic cage of $\mathrm{Pb}^{2+}$ ions) also decreases. This is possible since the coordination number of the $\mathrm{F}^{-}$ions is highest in $\mathrm{PbO}$-rich glasses and decreases from 6 to 3 in $\mathrm{PbF}_{2}$-rich glasses, as discussed in an earlier section. The decrease in coordination number results in a corresponding decrease in force constant and hence affects $T_{\mathrm{g}}$ in the observed manner.

\section{MICROHARDNESSES}

Vicker's microhardnesses for various glass compositions listed in table 1 show a slight increase with $\mathrm{PbO}$ content up to $60 \mathrm{~mol} \% \mathrm{PbO}$ and the values are roughly constant with higher percentages of $\mathrm{PbO}$. The values are comparable to (but lower than) the values reported for silicate and borate glasses containing very high percentages of $\mathrm{PbO}^{21,22}$ and higher than the values reported for purely ionic glasses. ${ }^{23}$ As addition of $\mathrm{PbF}_{2}$ to the glass is expected to make the glass structure more open, particularly on the $\mathrm{PbF}_{2}$-rich side, the decrease in microhardness with increasing $\mathrm{PbF}_{2}$ content is expected. This variation is also in agreement with the general observation that the addition of ionic constituents into network glasses reduces their microhardnesses. Note also that the microhardness values are slightly higher than those of $\mathrm{PbO}-\mathrm{PbCl}_{2}$ glasses. ${ }^{4}$

\section{CONCLUSIONS}

$\mathrm{PbO}-\mathrm{PbF}_{2}$ glasses have been obtained in the range $20-70 \mathrm{~mol} \% \mathrm{PbF}_{2} . \mathrm{X}$-ray diffraction studies indicate that the structures of these glasses are similar to those of $\mathrm{PbO}-\mathrm{PbCl}_{2}$ glasses. A structural model has been proposed for these glasses which suggests the presence of $\left[\mathrm{PbO}_{2} \mathrm{~F}_{4}\right]$-type units in the entire range of glass compositions. 
In glasses with high percentages of $\mathrm{PbF}_{2}$, fluoride ions are considered to play the role of oxygen ions in these glasses. All the thermodynamic properties studied vary in a manner consistent with the structural model and with the possible role of partly covalent $-\mathrm{O}-\mathrm{Pb}-\mathrm{O}-$ linkages. Isothermal variations of d.c. conductivity and activation energies as a function of composition are also consistent with the structural model.

We thank Prof. C. N. R. Rao, F.R.S., for his kind encouragement and the Indian Department of Science and Technology for financial support.

1 H. Rawson, Inorganic Glass Forming Systems (Academic Press, New York, 1967).

2 S. Shibata, T. Kanamori, S. Mitachi and T. Manabe, Mater. Res. Bull., 1980, 15, 129.

3 J-P. Miranday, C. Jacoboni and R. De Pape, J. Non-cryst. Solids, 1981, 43, 393.

4 K. J. Rao, B. G. Rao and S. R. Elliott, J. Mater. Sci., in press.

5 E. M. Rabinovich, Phys. Chem. Glasses, 1983, 24, 54.

6 L. V. Woodcock, C. A. Angell and P. Cheeseman, J. Chem. Phys., 1976, 65, 1565.

- C. Sandonnini, Athi. R. Accad. Sci. Torino, Cl. Sci. Fis., Mat. Nat., 1914, 22, 959.

8 J. W. Mellor, A Comprehensive Treatise on Inorganic and Theoretical Chemistry (Longman, London, 1927), vol. VIII, p. 703.

9 A. F. Wells, Structural Inorganic Chemistry (Oxford University Press, Oxford, 1975).

10 T. Furukawa, S. A. Brawer and W. B. White, J. Mater. Sci., 1978, 13, 268.

1 H. G. K. Sundar, B. Govinda Rao and K. J. Rao, Phys. Chem. Glasses, 1982, 23, 90.

12 P. S. L. Narasimham, S. Mahadevan and K. J. Rao, Proc. Ind. Acad. Sci., Part A, 1979, 88, 11.

13 B. G. Rao and K. J. Rao, Phys. Chem. Glasses, 1984, 25, 11.

14 K. J. Rao, J. Wong and B. G. Rao, Phys. Chem. Glasses, in press.

15 K. J. Rao and J. Wong, J. Chem. Phys., in press.

16 L. Pauling, Nature of the Chemical Bond (Cornell University Press, New York, 1960).

17 A. Hruby, Czech. J. Phys. Chem. B, 1972, 22, 862.

18 S. Chandra, Superionic Solids (North-Holland, Amsterdam, 1981).

19 C. A. Angell and W. Sichina, Ann. N.Y. Acad. Sci., 1976, 279, 53.

20 K. J. Rao and C. N. R. Rao, Mater. Res. Bull., 1982, 17, 1337.

21 J. D. Mackenzie, Molecular Behaviour of Materials (Society of Materials Science, Japan, 1972), vol. IV, p. 347.

${ }^{22}$ N. Shinkai, R. C. Bradt and G. E. Rindone, J. Mater. Sci., 1983, 18, 2466.

${ }^{23}$ H. G. K. Sundar and K. J. Rao, J. Chem. Soc., Faraday Trans. I, 1980, 76, 1617.

(PAPER 4/774) 